\title{
Gender analysis of students' entry qualification in English language in colleges of education in Kwara State
}

\author{
Olanipekun, Shola Sunday ${ }^{1}$, James Andokari Zaku \\ ${ }^{1}$ General Studies Department, College of Education (Tech.), Lafiagi, P.M.B 001, Kwara State, Nigeria \\ ${ }^{2}$ Department of English, School of Language, Federal College of Education, Zaria
}

\section{Email address:}

sholexofafrica@gmail.com(Olanipekun, S. S.), zakujames@yahoo.com(J. A. Zaku)

\section{To cite this article:}

Olanipekun, Shola Sunday, James Andokari Zaku. Gender Analysis of Students' Entry Qualification in English Language in Colleges of Education in Kwara State. International Journal of Secondary Education. Vol. 1, No. 5, 2013, pp. 23-25. doi: $10.11648 /$ j.ijsedu.20130105.12

\begin{abstract}
The paper employed descriptive survey study of students' entry qualification in English language based on gender in the Colleges of Education in Kwara State, Nigeria. One hundred and eighty- six students were sampled for the study. Descriptive Statistic was used to analyze the data collected. The results showed that male students performed better than their female counterparts. The paper concluded that findings on gender are inconclusive since different researchers have different opinions based on their findings as regards gender effect on students' academic performance. Recommendations were suggested at the end of the study.
\end{abstract}

Keywords: Gender, Entry Qualification, English Language, and Students’ Academic Performance

\section{Introduction}

It is pertinent to reveal that students' entry qualification in English language has become a basic criterion for students' admission into tertiary institutions in Nigeria and this is as a result of the notion that English language is a major language of instruction and textbooks [18]. Yet, based on students' academic performance,sex factor has become an area of educational interest to scholars that has generated conflict with inconclusive findings.

[14] averred that gender is an ascribed attributes that differentiates feminine from masculine socially. Gender could then be seen as cultural or social way of ascribing attributes which differentiates feminine away from masculine. The difference in academic interest and performance due to gender is a crucial matter to educationists.

Gender has been found to play an importance role in influencing students' academic performance and activities along with different factors such as intelligence, study habit, self-concept, creativity, aptitude, interests, reading culture and socio-economic status of the parent. Gender issues have become the talk of today's educational forum. Although, the literacy rate is more among boys than girls in every part of the world; it is quite interesting to observe that girls are securing better rank than boys in almost all academic circles and other competitive examinations [11]. To this effect; studies have shown that there exists distinction between boys and girls in their academic performance based on gender.

It is therefore safe to say on academic performance of secondary school students based on gender and year level and that significant gender differences exist in students' academic performance. The boys and girls differed significantly in drill, interaction and language [19]. In another study on the basis of gender, it was revealed that there is no significant difference in the performance of boys and girls in reading comprehension skills among senior secondary school students in Zaria Local Government Area of Kaduna State [17]

[11] in their study of academic performance of students in English language from gender lens in India made it known that the performance of the girls is higher than the boys. They indicated that there exists a significant difference between boys and girls. [9] also investigated gender difference in students' academic performance of girls and boys in schools in relation to English language in New Zealand. The study which employed a large sample of 5300 pupils showed that performance of girls in English language was significantly higher than that of boys both in term of mean curriculum coverage and examination's learning outcomes. The result however showed that the 
boys achieved significantly better results than the girls in mathematics.

In view of the above therefore, conclusion of scholars and researchers over gender in relation to academic performance varies. The more reason, generalization of results in a matter like this may be very difficult since the outcome of each research is based on so many other factors such as the data collected for the research.

\section{Research Question}

Is there any difference in the performance of the male and the female mean scores based on students' entry qualification in English language?

This research work employed descriptive survey method where students' scores in Colleges of Education in Kwara State based on entry qualification in English language, were collected and analyzed for the purpose of this study.

The sample population comprises of students from Colleges of Education in Kwara State. Pro-forma was used to collect students' scores from year 1 to year 3 (final year) students of 2011/2012 with a total number of one hundred and eighty six students that were randomly selected.

Research question was tested using descriptive statistic. Descriptive statistic is considered appropriate for this study because it gives concise description of performance of person or group and it enables us to compare two or more groups in terms of typical performance. Descriptive statistic summarizes a relatively large array of data into meaningful forms such that they could be more easily interpreted [16].

\section{Findings}

The result in Table 1 revealed that male students performed better than their female counterparts in English language in Colleges of Education in Kwara State based on students' entry qualification because the mean score of the males is higher than that of the females. In this sense, the research question is therefore answered.

Table 1. Male and female mean scores of students' entry qualification in English language

\begin{tabular}{llllll}
\hline & N & Minimum & Maximum & Mean & Std. Deviation \\
\hline Entry male & 99 & 40.00 & 61.00 & 49.6364 & 5.12388 \\
Entry female & 87 & 34.00 & 56.00 & 48.8276 & 5.38777 \\
Valid N (list & & & & \\
wise) & 87 & & & & \\
\hline
\end{tabular}

\section{Discussions}

The idea is to find out whether there is any significant correlation between male and female mean scores on the basis of performance in English language in relation to their entry qualification. The results therefore show that there is no significant relationship in the male and the female mean scores since the males outperformed their female counterparts in English language. This finding opposed several earlier findings that have unfolded the females to be the best in English language.

In this light, [1\&20] disclosed that the females showed a higher reading ability and culture in their academic performance than the males. [4]While they were analyzing the relationship between students' academic performance and intelligence in both boys and girls discovered that there is a correlation between academic performance and intelligence of the students and the correlation was greater in case of the girls than the boys. Thus, boys than girls are slow started at literacy and English language subject [8].

[10]On gender studies at Meijo University in Japan ascertained that female students outperformed their male counterparts in English language. In a similar study by [15] they opined that females do perform better than male students even though the females may enter the school with lower scores. In the same vein, [3] while investigating gender-based students' academic performance among the medical students safely stated that, the female medical students in Arab significantly outscored their male counterparts in most of the Basic medical science courses and most especially in English courses.

On the basis of who perform better in Science based on gender, [13] showed in his findings that females achieve better than the males in science. However, [2\&12] revealed that when total performance was independent of sex, the boys scored higher than girls in Mathematics, Physics and Science.

To this effect, gender lens as a factor in the academic performance of students either in English language or in any other subjects is not gender bias since either the male or the female could do well which is accountable for various summations of scholars on the issue of gender. Thus, it might be difficult to generalize the finding in this research unless further study is carried out on it.

\section{Conclusion}

It is thus very pertinent to revealed at this stage that studies on gender have showed that gender factor has effect on students' academic performance. However, the studies in gender differences in academic performance of students are highly controversial. The reason [5] opined that differences in gender as it affects students' academic performance are inconclusive. Hence, the studies above showed that different researchers have different opinions based on their findings as regards gender effect on students' academic performance.

\section{Recommendation}

1. It is believe that boys receive more numerous attentions and contacts with the teachers. Girls on the other hand tend to receive remedial help [6\&7] and this could be 
the major reason why there is significant difference in the performance of male and female students. However, teachers of English language should try to treat and give both gender equal attentions in the class.

2. Most of the government own tertiary institutions are without language laboratory and qualified teachers to handled English language. Government and others concerned stakeholders should ensure that more and qualified teachers are employed and language laboratory should be built where necessary.

\section{References}

[1] Agarwai, V.R. (1983).A study of reading ability in relation to certain cognitive and non-cognitive factors. Asian Journal of Psychology and Education, 11 (3);41-44.

[2] Aina ,J.K. \& Akintunde, Z.T. (2013). Analysis of gender performance in physics in Colleges of Education, Nigeria, Journal of Education and Practice, 4(6); 1 - 6

[3] Al-Mously , N., Salem, R. \& Al-Hamdan, N. (2013). The Impact of Gender and English language on Experience from New Saudi Medical School. Retrieved from www.scopemed.org/?mno $=30475$.

[4] Begun, S. \& Phukan, M. (2001). Academic achievement and intelligence: A correlational study in boys and girls. Indian psychological Review, 56 (2); 103-106.

[5] Buadi, J.Y. (2000). School and Personality as Correlates of Students' Attitudes to the School Guidance Services in Secondary Schools.Ph.D Thesis unpublished. Abraka: Delta State.

[6] Bullock, L.D. (1997). Efficacy of Gender and ethic equity in science education, curriculum for preserved teachers. Journal of Research in Science Teaching, 34(10); 10391065 .

[7] Buteyn, R.J.(1989). Gender and academic achievement in education. Retrieved from Eric Document Production Services No. E.D. 313103

[8] Cherry, C., Jane, K., Julie, M.(2001). Factors Influencing the Educational Performance of Males and Females in their Initiate Destination after Leaving School. A project funded by the commonwealth department of education, Training and youth affairs, Deakin University, University of South Australia.

[9] Harker, R. (2000). Achievement, gender, the single sex coeducation debate. British Journal of Sociology of Education, 21 (2);204- 218.
[10] John , C.W. (2006) .Gender and academic performance in English community courses in a Japanese University. Journal of the Institute for Second Language Development.Retrieved from www.Jisld/articles/genderperformance. Html.

[11] Karthigeyen, K. \& Nirmala, K. (2012). Academic achievement in English: Ananalys is through gender lens. MIER Journal of Educational Studies, Trends and Practices, $2(2) ; 144-157$

[12] Kaur, R . \& Gill, T.K (1993). Sex difference in academic achievement in different subjects of rural and urban students. Indian Psychological Review, 40 (2); $20-24$.

[13] Kurumah, M.S.(2004). Effect of ethno-mathematics approach on students' achievement in geometry and measurement. Journal of Mathematical Association of Nigeria. (MAN), 31 (1);35-44.

[14] Lee ,J.(2001).Interstate variations in rural student's achievement and schooling condition. Retrieved from hhp:/www.criedigest.org/2002-3/interstate-htm.

[15] Meltem, D. \& Serap, T. (2004). Gender differences in academic performance in a large public University in Turkey. Journal of Economics Research Centre, 17; 2- 11

[16] Nkemakolam, E.O. (2002). Designing and Conducting Research in Education. Owerri, Nigeria, Barloz publishers Inc.

[17] Oahimire, C.U. (2011). Effect of instruction in reading comprehension skills in senior secondary school students; inferential ability in Zaria. M.edThesis, Ahmadu Bello University, Department of Education, Faculty Of Education. Retrieved from www. Kubanni.abu.edu.ng:8080/JSPUI

[18] Olanipekun, S.S.(2012).Home factor as major psycho-social variable affecting students' academic performance in English language. Retrieved from www.articlebase.com/college=and-university-articles/homefactor-as-major-psycho-social-variable-affecting-studentsacademic-peroformance-633323

[19] Sueatha, B. \& Mayuri, K. (2001). A study on age and gender differences on the factors affecting high academic achievement. Journal of Community Guidance and Research, 18 (2); 197-208.

[20] Vijayalaxmi, N \& Natesan, V. (1992).Factors influencing academic achievement - a comparative study of government and private school students. Indian Psychology Review, 36 (2); 1-7. 